07

\title{
Дифракционная дилатометрия полиметилметакрилата в области низких температур
}

\author{
( Б.Ф. Фаррахов, Я.В. Фаттахов, М.Ф. Галяутдинов, А.Л. Степанов \\ Казанский фризико-технический институт им. Е.К. Завойского Казанского НЦ РАН, \\ 420029 Казань, Россия \\ e-mail: bulat_f@mail.ru
}

Поступила в редакцию 26.05.2017 г.

Измерен коэффициент линейного теплового расширения полиметилметакрилата в температурном диапазоне $-194-0^{\circ} \mathrm{C}$. Для дилатометрического исследования использовался метод оптической дифракции

DOI: $10.21883 /$ OS.2018.03.45663.126-17

\section{Введение}

Коэффициент линейного теплового расширения $\alpha(T)$ твердых тел, в частности полимеров, является одним из важнейших физических характеристик материалов, так как при различных температурных условиях существенно могут изменяться их геометрические размеры $[1,2]$. Несмотря на то что в литературе можно встретить достаточно много экспериментальных и теоретических работ, посвященных изучению зависимости $\alpha(T)$ для полимеров (например таких, как полиметилметакрилат (ПММА) [3-5]), исследования, как правило, проводились при температурах выше $0^{\circ} \mathrm{C}$. Например, в работе [3] опубликованы результаты экспериментального анализа $\alpha(T)$ для ПММА и его композитов в температурном диапазоне от 15 до $65^{\circ} \mathrm{C}$, а в работе [4] приводятся экспериментальные результаты и теоретические расчеты $\alpha(T)$ для того же полимера в области от 0 до $100^{\circ} \mathrm{C}$, которые описываются выражением $\alpha_{\text {PMмА }}=5.2 \cdot 10^{-5}+5.6 \cdot 10^{-7} T^{\circ} \mathrm{C}^{-1}$. Отметим, что в обеих публикациях была получена положительная линейная зависимость $\alpha(T)$, т.е. с ростом температуры происходит увеличение размера ПММА.

Возможность применения ПММА в условиях экстремально низких температур (например, в открытом космосе, в криогенных установках, в лабораторных экспериментах и т.д.) обусловливает актуальность дилатометрического изучения $\alpha(T)$ ПММА при температурах ниже $0^{\circ} \mathrm{C}$. С целью исследования зависимости $\alpha(T)$ ПММА при отрицательных температурах до $-194^{\circ} \mathrm{C}$ в настоящей работе была использована методика оптической дифракции [6-8]. Методика обладает достаточной точностью, а также позволяет проводить измерения бесконтактно и дистанционно на образцах малых размеров в несколько миллиметров. Дилатометрический анализ методом оптической дифракции заключается в регистрации дифракционной картины (ДК), получаемой при зондировании лазерным лучом предварительно сформированной на поверхности исследуемого образца дифракционной решетки (ДР). При этом регистрируется изменение угла дифракции выбранного дифракционного максимума или смещение проекции пучка на контрольной плоскости при изменении температуры образца. Изменение угла дифракции происходит за счет увеличения или уменьшения периода ДР вследствие линейного теплового расширения или сжатия твердого тела. Таким образом, измерив положение проекции дифракционного пучка на выбранной плоскости и измерив температуру образца, можно определить $\alpha(T)$. Отметим, что чувствительность метода зависит от ряда факторов: периода создаваемой ДР на исследуемом материале, длины оптического пути в регистрируемой схеме и от порядка наблюдаемого дифракционного максимума. Чем ближе период ДР к длине волны зондирующего лазерного излучения и чем выше порядок регистрируемого дифракционного максимума, тем выше точность измерения $\alpha(T)$ [6-8].

Настоящая работа является актуальной в связи с тем, что ПММА все больше заменяет обычное стекло при изготовлении оптических элементов приборов, оптоволокон, а также окон, иллюминаторов в авиаи машиностроении и др. К тому же как оптический материал ПММА находит свое применение в широком интервале положительных и отрицательных температур. Полиметилметакрилат является удобным для обработки материалом, известны различные способы изготовления ДР на его основе [9].

\section{Подготовка образцов}

В качестве исследуемого материала была использована пластина ПММА толщиной $2 \mathrm{~mm}$. Из пластины вырезались образцы с шириной $5 \mathrm{~mm}$ и длиной $10 \mathrm{~mm}$ для использования их в эксперименте с криостатом. На одной поверхности каждого из образцов создавалась фазовая ДР методом реплики с периодом $4 \mu \mathrm{m}$ (рис. $1, a$ ). Для формирования ДР на поверхность образца ПММА тонким слоем наносился жидкий ПММА и прижимался пластиной Si с предварительно сформированной фазовой ДР с периодом $4 \mu \mathrm{m}$. После полного затвердевания жидкого ПММА на поверхности образца была получена реплика ДР - точная копия решетки на пластине $\mathrm{Si}$.

Отделение реплики с ДР ПММА от пластины $\mathrm{Si}$ осуществлялось помещением образца в жидкий азот - 


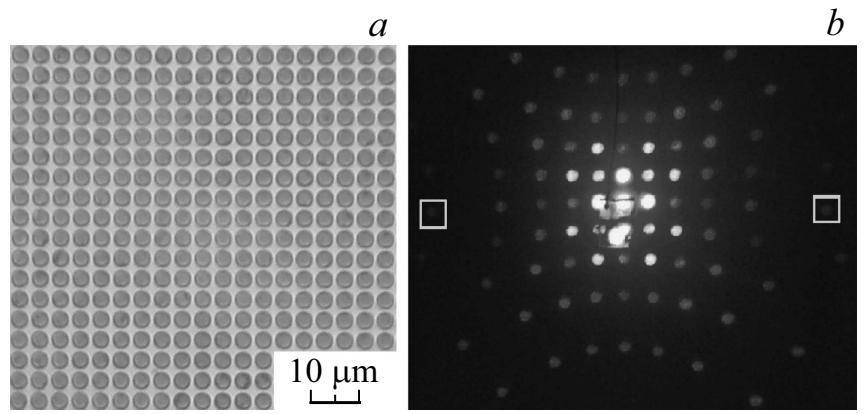

Рис. 1. Микрофотография ДР на поверхности ПММА, полученная интерференционным микроскопом МИИ-4 (a). Дифракционная картина, наблюдаемая на контрольном экране при зондировании образца ПММА Не-Ne-лазером на длине волны $0.6328 \mu \mathrm{m}$ на отражение $(b)$. Прямоугольниками выделены пятые дифракционные максимумы.
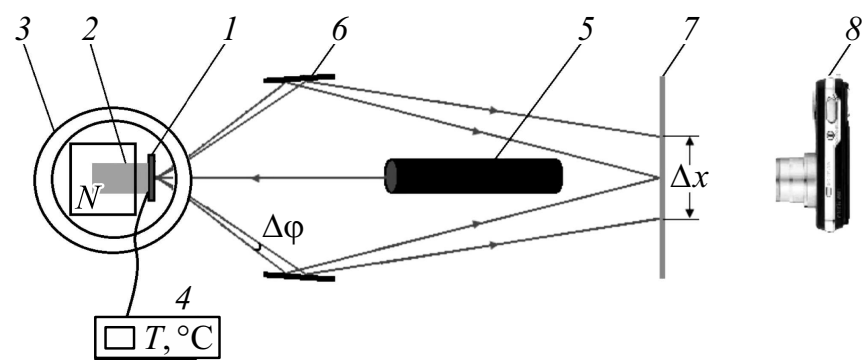

Рис. 2. Схема экспериментальной установки для исследования $\alpha(T)$ ПММА: 1 - образец с ДР, 2 - медный держатель образца, 3 - вакуумная камера, 4 - термопара, $5-\mathrm{He}-\mathrm{Ne}-$ лазер, 6 - зеркало, 7 - контрольный экран, $8-$ цифровая фотокамера, $\Delta x-$ смещение симметричных дифракционных максимумов пятого порядка друг относительно друга на контрольном экране.

вследствие отличия коэффициентов объемного теплового расширения ПММА и $\mathrm{Si}$ слой ПММА с ДР отслаивался от поверхности пластины $\mathrm{Si}$.

При зондировании данной ДР Не-Ne-лазером на длине волны $0.6328 \mu \mathrm{m}$ получается четкая ДК как на отражение, так и на пропускание (рис. $1, b)$. Интенсивность дифракционных максимумов ДР зависит от глубины рельефа $h$ периодической структуры и показателя преломления $n$ ПММА. В нашем случае $h \approx 200 \mathrm{~nm}$, $n=1.5$.

\section{Экспериментальные измерения}

Схема экспериментальной установки для исследования $\alpha(T)$ для ПММА в температурном диапазоне от -194 до $0^{\circ} \mathrm{C}$ представлена на рис. 2. Охлаждение образца ПММА (1), прикрепленного к медному держателю (2), проводилось жидким азотом в специальной вакуумной камере (3) с прозрачными окнами для обеспечения возможности зондирования и регистрации определенных симметричных дифракционных максимумов при лазерном облучении. Образец помещался в вакуумную камеру для предотвращения возникновения конденсата и образования льда на его поверхности.

Температура образца контролировалась с погрешностью $\pm 2{ }^{\circ} \mathrm{C}$ термопарой (4), подсоединенной к медному держателю (2). Оптическое зондирование ПММА с ДР производилось на отражение $\mathrm{He}-\mathrm{Ne}$-лазером ЛГН-111 (5) на длине волны $\lambda=0.6328 \mu \mathrm{m}$ при нормальном падении луча лазера на поверхность образца. Два симметричных дифракционных максимума 5-го порядка с помощью зеркал (6) совмещались на контрольном экране (7). Оптический путь от поверхности образца до экрана $L$ составлял $1.4 \mathrm{~m}$. Диаметр лазерного пятна на экране при таком расстоянии составлял $5 \mathrm{~mm}$. В процессе постепенного охлаждения образца происходило уменьшение периода ДР и соответственно смещались положения дифракционных пучков на экране друг относительно друга. Смещение регистрировалось цифровой камерой Exilim ex-f1 $(8)$ через каждые $20^{\circ} \mathrm{C}$ изменения температуры образца. По изменению расстояния между положениями дифракционных максимумов $(\Delta x)$ 5-го порядка на контрольном экране и показаниям термопары определялась $\alpha(T)$.

Вывод выражения, связывающего температуру материала $T$, смещения дифракционных пучков $\Delta x$ на контрольном экране и $\alpha(T)$ приведено ниже. Оно получается из уравнения линейного теплового расширения твердого тела и уравнения дифракции для плоской волны:

$$
\Delta d=\alpha(T) d \Delta T
$$

где $\Delta d-$ изменение периода ДР, $d-$ исходный период ДР, $\Delta T-$ изменение температуры образца. Это изменение периода вызывает соответствующее угловое перераспределение дифракционных максимумов разных порядков дифракции $k$ согласно уравнению ДР для плоской монохроматической волны, падающей по нормали к поверхности:

$$
\sin \varphi-\frac{k \lambda}{d},
$$

где $\varphi-$ угол дифракции, $\lambda-$ длина волны.

Для определения угловых изменений $\Delta \varphi$ в зависимости от $\Delta d$ дифференцируем уравнение (2):

$$
\cos \varphi \Delta \varphi=-\frac{k \lambda \Delta d}{d^{2}}
$$

и соответствующими преобразованиями уравнений (3) и (1) находим

$$
\alpha(T)=\frac{\Delta \varphi \sqrt{d^{2}-k^{2} \lambda^{2}}}{k \lambda \Delta T} .
$$

Учитывая, что

$$
\sin \Delta \varphi=\frac{\Delta x}{2 L}
$$

и $\Delta \varphi$ очень малая величина, получаем окончательное выражение для расчета $\alpha(T)$ :

$$
\alpha(T)=\frac{\sqrt{d^{2}-k^{2} \lambda^{2}}}{2 L k \lambda} \frac{\Delta x}{\Delta T} .
$$


Результаты измерения длины стержня ПММА в зависимости от $T$

\begin{tabular}{l|c|c|c|c|c|c|c|c|c|c|c}
\hline$T,{ }^{\circ} \mathrm{C}$ & -194 & -167 & -140 & -117 & -94 & -74 & -54 & -36 & -19 & 0 & 26 \\
\hline$S, \mathrm{~mm}$ & 650.5 & 651 & 651.5 & 652 & 652.5 & 653 & 653.5 & 654 & 654.5 & 655 & 656 \\
\hline$\Delta T,{ }^{\circ} \mathrm{C}$ & 220 & 193 & 166 & 143 & 120 & 100 & 80 & 62 & 45 & 26 & - \\
\hline$\Delta S, \mathrm{~mm}$ & 5.5 & 5 & 4.5 & 4 & 3.5 & 3 & 2.5 & 2 & 1.5 & 0.9 & - \\
\hline$a \cdot 10^{5},{ }^{\circ} \mathrm{C}$ & 3.81 & 3.94 & 4.13 & 4.26 & 4.46 & 4.57 & 4.76 & 4.92 & 5.08 & 5.27 & -
\end{tabular}

\section{Результаты и обсуждение}

На рис. 3, а показаны фотоснимки, на которых наблюдается смещение положения максимумов ДР на контрольном экране, и соответствующие этим смещениям значения температур для ПММА с ДР, по которым определялась зависимость $\alpha(T)$. Зависимость $\alpha(T)$ в температурном диапазоне от -194 до $0^{\circ} \mathrm{C}$, полученная из выражения (6), представлена на рис. 3, $b$. Как видно из рисунка, график имеет линейный характер, т.е. с уменьшением температуры образец ПММА сжимается.

Полученный линейный график (рис. $3, b$ ) можно описать функцией

$$
\alpha(T)=5.47 \cdot 10^{-5}+\left(0.92 \cdot 10^{-7}\right) T,
$$

где $T$ измеряется в ${ }^{\circ} \mathrm{C}$.

В отдельном эксперименте были проведены прямые измерения $\alpha(T)$ по изменению геометрических размеров образца ПММА при охлаждении жидким азотом. Для этого из ПММА вырезался стержень с фиксированными длиной $656 \mathrm{~mm}$ и шириной $10 \mathrm{~mm}$ при комнатной температуре $26^{\circ} \mathrm{C}$, который помещался в жидкий азот. При длительном выдерживании в хладагенте и достижении стержнем ПММА температуры жидкого азота стержень извлекался из азота и помещался на измерительный стол, где определялась его длина через каждые $0.5 \mathrm{~mm}$ удлинения по мере достижения стержнем комнатной

$\mathrm{cm} \quad a$

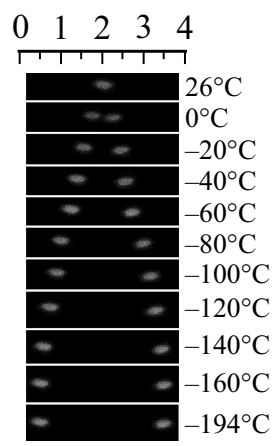

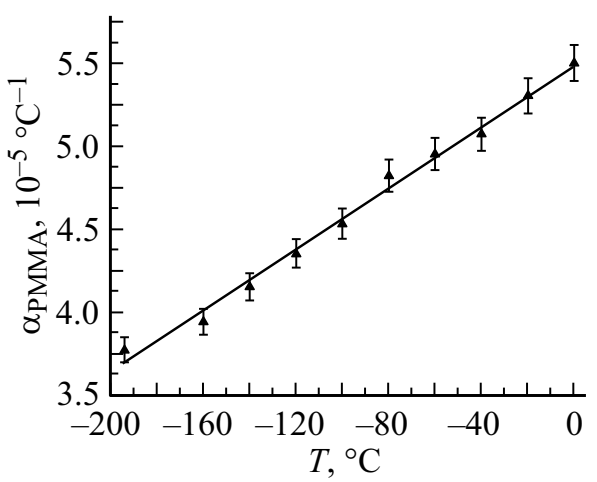

Pис. 3. Фотоснимки, демонстрирующие смещения дифракционных максимумов 5-го порядка на контрольном экране $(a)$, график $\alpha(T)$ ПММА $(\sigma)$.

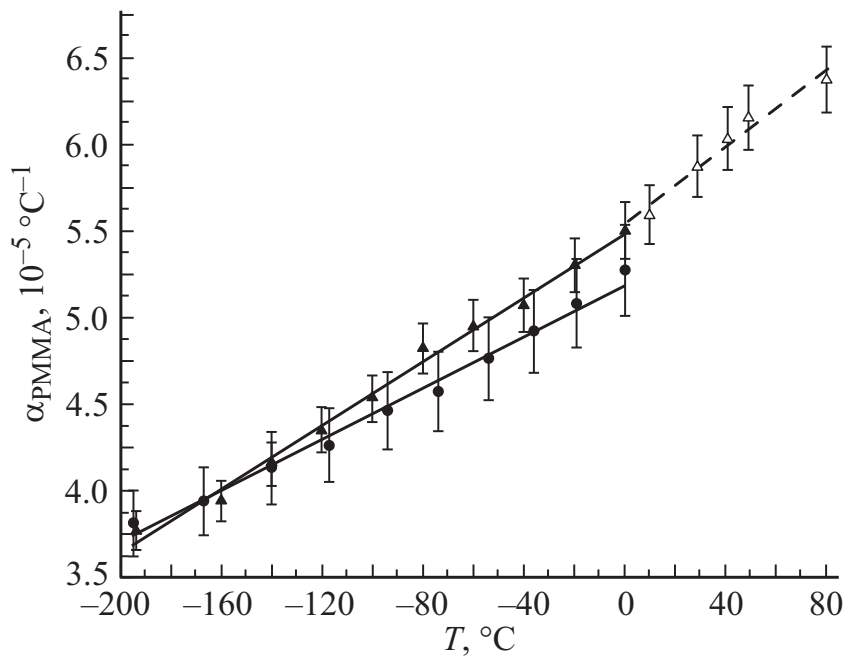

Рис. 4. \ - зависимость $\alpha(T)$ ПММА, полученная методом оптической дифракции в температурном диапазоне $-194-0^{\circ} \mathrm{C}$; - - зависимость $\alpha(T)$ ПММА, полученная прямым измерением длины и температуры в температурном диапазоне $-194-0^{\circ} \mathrm{C} ; \triangle-$ зависимость $\alpha(T)$ ПММА, полученная методом оптической дифракции при положительных температурах (приведен для сравнения).

температуры. Температура также измерялась термопарой. При выдерживании стержня ПММА в жидком азоте его длина уменьшалась вследствие сжатия. Далее в процессе постепенного нагрева образца до комнатной температуры $26^{\circ} \mathrm{C}$ наблюдалось постепенное увеличение и восстановление его исходной длины (см. таблицу). По изменению геометрического размера стержня определялась зависимость $\alpha(T)$ :

$$
\alpha(T)=\frac{\Delta S}{S \Delta T}
$$

где $S$ - длина стержня ПММА при комнатной температуре $26^{\circ} \mathrm{C}, \Delta S$ - изменение длины стержня, $\Delta T-$ изменение температуры. Полученная в данном эксперименте зависимость $\alpha(T)$ приведена на рис. 4. Из графиков следует, что результаты измерения $\alpha(T)$ ПММА в температурном диапазоне от -194 до $0^{\circ} \mathrm{C}$ методом оптической дифракции в пределах погрешности согласуются с результатами, полученными прямым методом. Также для сравнения на рис. 4 приведен график $\alpha(T)$ ПММА, полученный при положительных температурах. 


\section{Заключение}

Впервые проведены дилатометрические измерения ПММА при температуре ниже $0^{\circ} \mathrm{C}$. Установлено, что в температурном диапазоне от -194 до $0^{\circ} \mathrm{C}$ значения $\alpha$ ПММА изменяется по линейному закону. Полученные результаты измерения $\alpha(T)$ ПММА методом оптической дифракции показывают принципиальную возможность измерения $\alpha(T)$ твердых тел (полимеров) при низких температурах.

\section{Список литературы}

[1] Новикова С.И. Тепловое расширение твердых тел. М.: Наука, 1974. 293 с.

[2] Мазурин О.В. и др. Тепловое расширение стекла. М.: Наука, 1969. 219 с.

[3] Jindal P., Gupta Sh., Bansal S., Gairola, Pandey S.K., Singh A.P., Bhandari R. // IJRMET. 2014. V. 4. N 2. P. 72.

[4] Goods S.H., Watson R.M. Thermal Expansion and Hydration Behavior of PMMA Molding Materials for LIGA Applications. California.: Sandia National Laboratories, 2003. $57 \mathrm{p}$.

[5] Hadač J., Slobodian P., Sáha P., Řiha P. // Chemické listy. 2014. V. 108. SPEC. ISSUE 1. P. s50.

[6] Магунов А.Н. Лазерная термометрия твердых тел. М.: Физматлит, 2001. 224 с.

[7] Галяутдинов М.Ф., Фаррахов Б.Ф., Фаттахов Я.В., Захаров М.В. // Опт. и спектр. 2009. Т. 107. В. 4. C. 675. Galyautdinov M.F., Farrakhov B.F., Fattakhov Ya.V., Zakharov M.V. // Opt. Spectr. V. 107. N 4. P. 640.

[8] Фаррахов Б.Ф., Фаттахов Я.В., Галяутдинов М.Ф., Степанов А.Л. // Материаловедение. 2017. № 2. С. 55.

[9] Галяутдинов М.Ф., Нужоин В.И., Фаттахов Я.В., Фаррахов Б.Ф., Валеев В.Ф., Осин Ю.Н., Степанов А.Л. // Письма в ЖТФ. 2016. Т. 42. № 4. С. 30. 